\title{
Using Technology in Learning Integral Calculus
}

\author{
Effandi Zakaria ${ }^{1}$ \\ Tuan Salwani Salleh² \\ ${ }^{1}$ Department of Teaching and Learning Innovation, Faculty of Education, Universiti Kebangsaan Malaysia, Malaysia \\ Email: effandi@ukm.edu.my \\ ${ }^{2}$ Mathematics Section, Universiti Kuala Lumpur Malaysia France Institute, Bandar Baru Bangi, Selangor, Malaysia
}

\section{Doi:10.5901/mjss.2015.v6n5s1p144}

\begin{abstract}
The purpose of this study was to investigate students' perceptions towards integral calculus difficulty and their readiness towards using technology in learning integral calculus. A total of 191 students were selected at random from two lecture groups of Technical Mathematics 1. The students were given a set of questionnaire with two parts. The first part was used to measure students' perceptions on integral calculus difficulty. The second part was used to measure students' computer readiness in learning. Three main contributing factors of students' readiness towards computers were adapted from The Computer Aversion, Attitudes, and Familiarity Index (CAAFI).For measuring computer readiness using CAAFI, Pearson correlations and the mean values were determined. The inter-correlations between factors in this instrument were statistically significant. More than three quarters of the students with school calculus background perceived integral calculus as difficult or a very difficult topic. The students were found to have positive attitudes towards computers, a low computers aversion level and an average level of computers familiarity. These findings allow for an enhancement of teaching and implementation of learning calculus using computers.
\end{abstract}

Keywords: Integral calculus, Computer readiness, Computer attitudes, Computer aversion, Computer familiarity.

\section{Introduction}

Calculus is one of the fundamental courses in mathematics and has been introduced into the secondary school curriculum in Malaysia as one of the options in form four and form five mathematics. It provides a foundation and a gateway for more advanced mathematics (Tall, 1997). This topic is of vital important to the success of any science and engineering fields, including engineering technology (Cheshier, 2006; Kent \& Noss, 2000). One of the two fundamental concepts in this topic is integral calculus. Therefore, it is critical for students taking engineering and science to excel in calculus, including integral calculus. A growing body of research has shown that students have difficulties in understanding the concept of integral calculus (Mahir, 2009; Salleh \& Zakaria, 2011; Abdul Rahman, 2005).

Orton (1985) highlighted a few old, yet still relevant points to the teaching and learning of calculus reported by Incorporated Association of Assistant Masters in 1957. One of the main points emphasized is related to the teaching of calculus, where this topic needs the most cautious introduction and development. The consequence of introducing this subject without a proper planning and approach is too risky to students' future understanding about the subject related to calculus. He added that educators should never let students go through the differentiation and integration lessons procedurally without a deep understanding of the underpinning concepts (Orton, 1985).

According to Tall (1992), the first time students were introduced to calculus, they were exposed to calculations that involved complicated arithmetic and algebra. Thus, to avoid the difficulties, teachers often oversimplify the calculations (Tall, 1992). He added that this fact has contributed to the emergence of calculus dissatisfaction. In addition, with the incorrect pedagogical attitudes of teachers, students tend to choose memorizing steps of solving mathematical problems (Akgün, et al., 2010). They also concluded that this strategy has given a negative effect on students' thinking processes. Besides, an appropriate time allocation in learning calculus during high school is also crucial to ensure the understanding of the first year university calculus (Burton, 1989). Burton has stated that "the lack of the year of high school calculus can seriously handicap the first-year university student, who must compete with a significant proportion of classmates for whom the subject is not new." All of these factors have contributed to the low performance of calculus.

One private university in Malaysia that offers Engineering Technology undergraduate courses has recurrently faced the negative impact. The analysis of calculus performance of the students at the university, particularly in the 
integral calculus topic was found to be low. Only $6.8 \%$ students manage to pass the topic (Salleh \& Zakaria, 2011). There were many reasons why students faced difficulties in calculus. Mahir (2009) has highlighted the deficiency in conceptual understanding as one of them. The engineering technology field has extra reasons behind the low mathematics achievement. The reasons are basically related to the nature of the field itself where the backbone of Engineering Technology curricula is the experiential learning (Barbieri \& Fitzgibbon, 2008). Students need to be exposed to a handson learning strategy, whereas the current teaching strategy does not fit the character of engineering students (Kocsis, 2007). Apart from that, the time allocated for mathematics lessons is decreasing. This scenario happens due to the increased numbers of technical subjects.

Whatever reasons behind the high failure rate, this problem needs serious attention from educators at the private university because calculus is the foundation for more advanced mathematics, as well as in technical subjects. Therefore, an immediate plan need to be considered because failure in calculus will accumulate many more failures in calculus related subjects and hence it will affect the number of students graduating on time.

One possible mean of reducing the failure rate of this subject is to improve the teaching and learning of this subject at the university involved. Kocsis (2007) highlighted that an abstract subject like mathematics needs to have new tools to motivate students. Moreover, he claims that students need to understand different applications of the vast amount of information learned in the classroom. The current teaching and learning approach in this university is mass lecture and small tutorial groups' discussions. Students are exposed to new materials in lecture and during the tutorial slot; they will try to complete the exercises given by their lecturer. However, through scrutinizing information from students' evaluation forms and interviewing lecturers involved, this approach does not promote students' deep understanding. The studies conducted by mathematics educators worldwide in improving the teaching and learning of calculus have shown that the positive impacts on students' understanding can be obtained through technology integration(Berry, et al., 2008; Cook, 2006; Kocsis, 2007; Noinang, et al., 2008; Wiwatanapataphee, et al., 2010). Therefore, the enhancement of current teaching and learning of integral calculus in this university can be done through adapting a similar approach.

Computer algebra system (CAS) has the capability to manipulate algebraic symbolic forms of an equation. It has been widely used to support teaching and learning of mathematics at the university (Noinang et al., 2008; Robinson \& Burns, 2009; Wiwatanapataphee et al., 2010). Nowadays, many symbolic packages have been developed using Mathematica software and Maple software. These symbolic packages enable students to understand the concepts taught better with the availability of their visual supports (Noinang et al., 2008). CAS is also capable of saving a lot of calculation time. Furthermore, CAS facilitates the balance, the sequence, and the priorities of conceptual and procedural knowledge in the mathematics curriculum (Heid, 2001). However, the paradigm shift in the teaching and learning of this subject cannot be implemented abruptly without a proper investigation of students' readiness in using this technology. Therefore, with this point in mind, the purposes of this study are to investigate the engineering technology students' perceptions towards the difficulty level of the calculus topic and towards computer usage in learning.

\section{Materials and Methods}

This study employs a survey method to identify students' most problematic topic in mathematics and to investigate their readiness towards learning the topic using CAS. Two survey sessions were conducted by two different mathematics lecturers at the university involved. One set of questionnaire was administered to 191 students randomly chosen from the group of students who enrolled in Technical Mathematics 1 . The instructions in the questionnaire were clearly explained by both lecturers. The questionnaire was written in two different parts, Part A and Part B. Part A was developed to gather information regarding students' academic backgrounds related to calculus. In one of the questions in this part, students were asked to rank the difficulty level of topics in one of the secondary school mathematics option subjects, known as Additional Mathematics. This question is only applicable to those taking Additional Mathematics during their upper secondary school. Since there are five topics in Additional Mathematics, the students portrayed their perception towards the difficulty level of calculus by stating a value ranging from 1 (the easiest topic) to 5 (the most difficult topic).

Items in Part B were adapted from the finalized version of The Computer Aversion, Attitudes, and Familiarity Index (CAAFI) items developed by Schulenberg and Melton (2008). CAAFI consists of 30 items with three main factors: Computer Attitudes, Computer Aversion, and Computer Familiarity. The students' perception towards computer usage was examined through these three main factors. Each factor is comprised of ten items (Schulenberg \& Melton, 2008). The original CAAFI is a seven-point response item, ranging from -3 (absolutely false) to +3 (absolutely true). In this study, the scale has been modified to a five-point Likert scale ranging from 1 (strongly disagree) to 5 (strongly agree). A total of eight items in CAAFI (item 6, 8, 9, 15, 17, 24, 25, and 26) are negative items and have been re-coded to the reverse score. In this study, the original language used in the instrument was maintained because the medium of instruction at 
the university involved is English.

CAAFI was designed by Schulenberg et al. to suggest affinity towards computers (Schulenberg \& Melton, 2008). CAAFI consists of items related to students' computer attitudes, computer aversions, and computer familiarity. The internal consistency reliability of the items in the instrument used (CAAFI) was analyzed using SPPS 18 software to ensure the reliability of the instrument in this study's setting. In this study, three factors in CAAFI were used to reflect on students' readiness in learning integral calculus with computers. The items of each factor in CAAFI were summed and the mean score for each factor was measured by dividing the summation value by the total number of items in the respective factor. Higher mean score value indicates less aversion, more familiarity, and more favorable attitudes toward computers. In this study, students' readiness was considered high if they have a high positive attitude, low aversion level, and high computer familiarity.

\section{Results and Discussion}

A total of $101(52.9 \%)$ students involved in this study have an experience learning calculus during their secondary schooling. However, only $2 \%$ of the students scored an "A-" and "A" and $5.9 \%$ of them achieved a "B" and "B-" in Additional Mathematics. On the other hand, the percentage of the students who scored a " $\mathrm{D}$ " and below was very high. Almost $70 \%$ of them scored either a "D" or lower with $30.7 \%$ of them failing the subject. From these findings, it can be recommended that students who chose to enroll in Engineering Technology courses at the diploma level in this university were lacking a strong calculus foundation.

In terms of the students' perception towards the difficulty level of calculus including integral calculus, $78.2 \%$ of them either ranked calculus as difficult or very difficult with $40.6 \%$ admitting that the topic is the most difficult in Additional Mathematics. On the contrary, only $5 \%$ of them claimed the topic is the easiest in the subject. Their perceptions towards secondary school calculus were supported by their poor performances during upper secondary school. At the university level, the perceptions were proven by a low achievement in calculus by the January - June 2010 cohort. The students from that cohort performed poorly in this topic during their second semester's Technical Mathematics 2. About93.2\% of them did not manage to pass calculus in the July - November 2010 final examination (Salleh \& Zakaria, 2011). This information gives the mathematics educators at the university an obvious clue to revamp the strategy of teaching and learning of this topic. Thus, a new strategy involving an integration of computer technology in the teaching and learning of calculus will be designed. But prior to that, students' readiness towards using computers in learning the topic was investigated in this study using CAAFI.

The internal reliability value of CAAFI obtained was 0.86 . This value indicates that the internal consistency reliability coefficient of CAAFI in this setting is excellent(Pallant, 2011). This reliability value is consistent with the data published in the previous studies on CAAFI (Schulenberg \& Melton, 2008; Schulenberg et al., 2006).Supports for validity of CAAFI were proven by statistically significant inter-correlations between all three factors. Correlations among the CAAFI factors' scores were statistically significant at $p<0.01$. The inter-correlations between the CAAFI factors' scores are comparable to those reported in Schulenberg et al. (2006) and Schulenberg et al. (2008). The correlations between computer attitudes with computer aversion and computer familiarity were 0.54 and 0.59 respectively. These values are considered large (Pallant, 2011) and indicate a strong relationship between the factors. However, the correlation between computer aversion and computer familiarity was 0.39 and it is considered a medium correlation value (Pallant, 2011). The reliability and correlation of items in CAAFI obtained in this study permit the intended analysis of investigating students' readiness towards using computers in learning being carried on.

The mean score value for computer attitude was the highest mean value obtained among the three factors in CAAFI (Table 1). The value 4.02 out of 5 tells us that the students involved in this study have a very high positive value towards using computers in their daily activities. The computer aversion's mean score of 3.94 indicates that the level of students' aversion was low. This result suggests that students' perception towards computer usage were positive. The mean score of computer familiarity was at the average level. However, this value may not affect their readiness to use computers in learning since they have a very high positive attitude level and a high liking level towards computers. These circumstances have provided the impetus for researchers to further examine the integration of technology in the teaching and learning of integral calculus. 
Table 1: The mean score of Computer Attitude, Computer Aversion, and Computer Familiarity

\begin{tabular}{|c|c|c|}
\hline Factors & Mean & Interpretation \\
\hline Computer Attitude & 4.02 & Students involved in this study have a very high positive attitude towards computers. \\
\hline Computer Aversion & 3.94 & $\begin{array}{l}\text { Since all negative items were re-coded to the reverse score, this value indicates that students } \\
\text { in this survey have a very low computer aversion level. }\end{array}$ \\
\hline Computer Familiarity & 3.27 & The level of computer familiarity of the students involved in this study was at an average level. \\
\hline
\end{tabular}

From the findings, it can be concluded that students who enrolled in Engineering Technology courses at the university involved were found to have a low calculus foundation. In addition, more than $75 \%$ of them perceived calculus as a difficult or very difficult topic. However, their readiness towards using computers in learning was found to be high. This allows for an enhancement of teaching and the implementation of learning calculus using computers to improve their calculus performance. This is parallel to the needs in learning calculus in its optimal environment, which is a software adoption teaching and learning paradigm (Colonna \& Easley, 2011). Nordin et al. (2010) emphasized that the usage of technological tools in mathematics classes will produce generations who are not only information communication technology (ICT) literate but also knowledgeable mathematically.

\section{Conclusion}

The results obtained from exploring students' perceptions towards calculus and their readiness to use computers in learning provides a new perspective on the teaching and learning of this topic. Engineering Technology students enrolled in the university involved in this study basically lack a strong calculus foundation. Furthermore, three quarters of the students ranked calculus as a difficult topic. A weak calculus foundation and negative perceptions toward calculus cannot be ignored, as mathematics is one of the core subjects in engineering technology. These limitations can be overcome through an appropriate approach. Since engineering technology students' nature of learning is an experiential learning approach, active learning is a practical approach to be considered. Integrating computers in the learning of calculus should be seriously considered as many studies have shown a positive impact of this strategy on students' understanding. Thus, the new strategy has to be carefully planned in improving students' learning outcomes in calculus.

\section{References}

Abdul Rahman, S. (2005). Learning with examples and students' understanding of integration. Paper presented at the Reform, Revolution and Paradigm Shifts in Mathematics Education, Johor Bahru, Malaysia. http://math.unipa.it/ grim/21.../21_malasya_ AbdulRahman24-28_05.pdf (Accessed on May 2,2014)

Akgün, L., Isleyen, T., Tatar, E., Soylu, Y., \& Duru, A. (2010). Comprehension test in calculus course. Procedia Social and Behavioral Sciences 2(2), 1527-1531. DOI: 10.1016/j.sbspro.2010.03.229

Barbieri, E., \& Fitzgibbon, W. (2008). Transformational paradigm for engineering and engineering technology education. Paper presented at the 2008 IAJC-IJME International Conference. http:// digital.library.unt.edu/ark:/67531/metadc115194/ (Accessed on Sept 4, 2013)

Berry, J. S., Lapp, D. A., \& Nyman, M. A. (2008). Using technology to facilitate reasoning: lifting the fog from linear algebra. Teaching Mathematics and Its Applications, 27(2), 102-111. Doi:10.1093/teamat/hrn005

Burton, M. B. (1989). The effect of prior calculus experience in "introductory" college calculus. American Mathematical Monthly, 96, 350 354. DOI: $10.2307 / 2324093$

Edwards, C.H. Jr. (1979). The Historical Development of the Calculus. New York: Springer-Verlag New York Inc. ISBN 978-1-4612-62 30-5

Cheshier, S. R. (2006). The Field of Engineering Technology Studying Engineering Technology: A Blueprint for Success. ISBN: 096469 6932

Colonna, F., \& Easley, G. (2011). Hints on how to improve mathematics instruction. Journal of e-Learning and Knowledge Society, 7(1), 7-20. http:// www.editlib.org/d/43332/ (Accessed on Oct,2013)

Cook, D. (2006). Maple graphing tools for calculus III. Mathematics and Computer Education, 40(1), 36-41. http:// eric.ed.gov/?id=EJ7 69584

Heid, M. K. (2001). Theories that inform the use of CAS in the teaching and learning of mathematics. Paper presented at the CAME Symposium. http:// www.lkl.ac.uk/research/came/events/.../3-Presentation-Heid.pdf (Accessed on Jan 2, 2012)

Kent, P., \& Noss, R. (2000). The visibility of models: using technology as a bridge between mathematics and engineering. International Journal of Mathematical Education in Science and Technology, 31(1), 61-70. http://eprints.ioe.ac.uk/1497/ (Accessed on Feb 20, 2012)

Kocsis, I. (2007). Application of Maple ODE analyzer in investigation of differential equations in higher engineering education. An 
International Journal for Engineering and Information Sciences, 2(Suppl.), 177-183. DOI: 10.1556/Pollack.2.2007.S.16

Mahir, N. (2009). Conceptual and procedural performance of undergraduate students in integration. International Journal of Mathematical Education in Science and Technology, 40(2), 201-211. DOI:10.1080/00207390802213591

Noinang, S., Wiwatanapataphee, B., \& Wu, Y. H. (2008). Teaching-Learning Tool for Integral Calculus. Paper presented at the The 13th Asian Technology Conference in Mathematics, Suan Sunandha Rajabhat University, Bangkok, Thailand. http://atcm. mathandtech.org/EP2008/papers_full/2412008_17503.pdf (Accessed on May 8, 2012)

Nordin, N., Zakaria, E., Mohamed, N. R. N., \& Embi, M. A. (2010). Pedagogical usability of the Geometer's Sketchpad (GSP) digital module in the mathematics teaching. The Turkish Online Journal of Educational Technology 9(4), 113-117. http:// http://www. tojet.net/articles/v9i4/9411.pdf (Accessed on Sep 8, 2012)

Orton, A. (1985). When should we teach calculus? Mathematics in School, 14(2), 11-15. http:// http://www.jstor.org/stable/30213968 (Accessed on Oct 2, 2012)

Pallant, J. (2011). SPSS Survival Manual: A Step by Step Guide to Data Analysis Using SPSS (4th ed.). Crows Nest, NSW: Allen \& Sunwin. ISBN: 9780335242399

Robinson, T., \& Burns, C. (2009). Computer Algebra Systems and Their Effect on Cognitive Load. Paper presented at the The 9th International Conference on Naturalistic Decision Making, London, UK. http://www.bcs.org/upload/pdf/ewic_ndm09_s4paper8.pdf (Accessed on Nov 2012)

Salleh, T. S. A., \& Zakaria, E. (2011). Integrating computer algebra system (CAS) into integral calculus teaching and learning at the university. International Journal of Academic Research, 3(3), 397-401. http://connection.ebscohost.com/c/articles/69707618/ integrating-computer-algebra-systems-cas-integral-calculus-teaching-learning-university (Accessed on Dec 12, 2012)

Schulenberg, S. E., \& Melton, A. M. A. (2008). The computer aversion, attitudes, and familiarity index (CAAFI): A validity study. Computers in Human Behaviour, 24(6), 2620-2638. DOl: 10.1016/j.chb.2008.03.002

Schulenberg, S. E., Yutrzenka, B. A., \& Gohm, C. L. (2006). The computer aversion, attitudes, and familiarity index (CAAFI): A measure for study of computer-related constructs. Journal of Educational Computing Research, 34(2), 129-146. http:/www.editlib.org/ p/69235/ (Accessed on Feb 20, 2011)

Tall, D. (1992). Students' difficulties in calculus. Paper presented at the International Congress on Mathematical Education (ICME 7), Quebec, Canada. http://homepages.warwick.ac.uk/staff/David.Tall/pdfs/dot1993k-calculus-wg3-icme.pdf (Accessed on Mac 2, 2012)

Tall, D. (1997). Functions and calculus. In A. J. Bishop, K. Clements, C. Keitel \& J. Kilpatrick (Eds.), International Handbook of Mathematics Education (pp. 289-325). Dordrecht: Kluwer. ISBN: 9780792335337

Wiwatanapataphee, B., Noinang, S., Wu, Y. H., \& Nuntadilok, B. (2010). An Integrated Powerpoint-Maple Based Teaching-Learning Model for Multivariate Integral Calculus. International Electronic Journal of Mathematics Education, 5(1), 5-31. http://www.iejme. com/012010/d2.pdf (Accessed on May 4, 2013) 